\title{
Expression of long non-coding RNA DLX6-AS1 in lung adenocarcinoma
}

\author{
Juan Li ${ }^{1}$, Ping Li ${ }^{1}$, Wei Zhao ${ }^{2}$, Rui Yang ${ }^{1}$, Shanshan Chen ${ }^{1}$, Yong Bai ${ }^{1}$, Shaozhi Dun ${ }^{1}$, Xiaonan Chen ${ }^{3}$, Yuwen Du ${ }^{3}$, \\ Yuanyuan Wang ${ }^{3}$, Wenqiao Zang ${ }^{3}$, Guoqiang Zhao ${ }^{3}$ and Guojun Zhang ${ }^{1 *}$
}

\begin{abstract}
Background: Lung adenocarcinoma (LAC), the primary histological type of non-small cell lung cancer (NSCLC), has displayed an increasing incidence and mortality worldwide. However, therapeutic approaches were limited. Dysregulation of some IncRNAs has been shown in various types of cancers including LAC. The aim of the present study was to vertify IncRNA DLX6-AS1 expression in LAC.

Methods: Microarray assay revealed expression profile of IncRNAs in LAC. qRT-PCR ( quantitative reverse transcription PCR) was performed to identify IncRNA DLX6-AS1 expression level in 72 paired LAC and adjacent normal lung tissues. qRT-PCR and Western blotting were used to verify that down-regulation IncRNA DLX6-AS1 decreased DLX6 (distal-less homeobox 6) mRNA and protein expression.

Results: Microarray analysis identified up-regulation of 272 IncRNAs and down-regulation of 635 IncRNAs in LAC tissues. The expression level of IncRNA DLX6-AS1 in LAC tissues was significantly higher compared to paired adjacent normal lung tissues $(P<0.05)$. In addition, its expression level was closed correlated with both histological differentiation $(P=0.004)$ and TNM stage $(P=0.033)$. qRT-PCR and Western blotting analysis showed that DLX6 mRNA and protein levels were lower in si-LncRNA group than in the NC (negative control) and Blank groups.

Conclusions: Microarray analysis identified that IncRNA DLX6-AS1 was up-regulated in LAC tissues. High DLX6-AS1 expression levels were significantly associated with both histological differentiation and TNM stage. Down-regulation of IncRNA DLX6-AS1 expression decreased the DLX6 mRNA and protein levels.
\end{abstract}

Keywords: IncRNA DLX6-AS1, LAC, Microarray assay, DLX6

\section{Background}

With an ascending incidence in recent year, lung cancer is now the mostly commonly diagnosed malignancy worldwide, representing the leading cause of cancer-related death [1-3]. In 2014, an estimated 224,210 new cases will be diagnosed, of which the majority are probably nonsmall cell lung cancer (NSCLC) and at advanced stage meanwhile [4]. NSCLC including adenocarcinoma and squamous cell carcinoma, is a predominant form of lung cancer [5]. Despite the improvement achieved in chemotherapy and radiotherapy over the past few decades, the prognosis for patients with NSCLC is still dismal, with 5 -year survival rate slightly more than 15\% [6]. Lung

\footnotetext{
* Correspondence: gjzhangzzu@126.com

'Department of Respiratory Medicine, The First Affiliated Hospital of

Zhengzhou University, Zhengzhou, Henan, China

Full list of author information is available at the end of the article
}

adenocarcinoma (LAC) accounts for more than $50 \%$ of all NSCLC and its incidence has been increasing recently [6,7]. Thus, it is urgent to find new prognostic markers and therapeutic strategies to improve the present situation. Recently, growing evidence indicates that non-coding RNAs may be involved in cancer pathogenesis, providing new insights into the biological progress of LAC $[8,9]$.

The human genome project revealed that at least $90 \%$ of the human genome is actively transcribed to RNA, but less than $2 \%$ of RNA encodes proteins [10,11]. Noncoding RNAs (ncRNAs), including microRNAs (miRNAs), long non-coding RNAs (lncRNAs), tRNAs, snoRNAs, and siRNAs, are functional RNAs that don't encode proteins $[12,13]$. LncRNAs are known to play important roles during cellular development and differentiation, and a large range of biological processes, such as modulation of 
tumor proliferation and invasiveness, and reprogramming of induced pluripotent stemcells $[14,15]$. Dysregulation of some lncRNAs has been shown in various diseases including cancers, such as breast cancer, hepatocellular carcinoma, melanoma, bladder cancer, prostate cancer, gastric cancer and skin cancer [16-27]. For example, HOTAIR, has been determined as a negative prognostic indicator in breast, liver and pancreatic cancer, representing a close association especially with breast cancer metastasis $[28,29]$. Takahashi's study demonstrated that PVT1 expression levels in colorectal cancer tissues were significantly higher than that in non-cancerous tissue, and patients with high PVT1 expression had a significantly poorer prognosis, what's more, knockdown PVT1 expression could promotes apoptosis in colorectal cancer cells [30]. Metastasis associated lung adenocarcinoma transcript 1 (MALAT1) was found to be over expressed not only in breast, pancreas, colon, prostate, and liver cancers, but also in early-stage metastasizing NSCLC [31,32].

However, the functions of lncRNAs in lung cancer remain unclear. We investigated microarray data of lncRNAs from 3 paired LAC tissues and adjacent normal tissues, then focused on lncRNA DLX6-AS1 (distal-less homeobox 6 antisense 1). Up to now, there is no relevant report about the relationship between IncRNA DLX6-AS1 and the progression of LAC. The aim of the present study was to vertify lncRNA DLX6-AS1 expression in LAC tissues and adjacent normal tissues, then to explore the relationship between lncRNA DLX6-AS1 expression and clinicopathological features and to test the expression of DLX6 mRNA and protein in LAC cell lines after transfection with siRNA of lncRNA DLX6-AS1. The study may provide a new perspective on the diagnosis and treatment for this deadly disease.

\section{Results}

Microarray data analysis

A total of 907 lncRNAs were demonstrated with differential expressions ( $\log _{2}$ fold change $(\mathrm{T} / \mathrm{N} \geq 2$ or $\leq-2)$ between tumor tissues and adjacent normal tissues from 3 LAC patients. Microarray analysis identified that 272 lncRNAs were up-regulated including lncRNA DLX6AS1, whereas 635 lncRNAs were down-regulated in LAC tissues. Part of lncRNAs expression levels are shown in Table 1. The heat map of the hierarchical clustering results was performed to vertify part of the distinguishable lncRNAs expression profile among 3 paired LAC and adjacent normal tissues (Figure 1a). The scatterplot results showed that the distribution and expression variation of the $\log 2$ ratios of lncRNAs were similar among 3 paired LAC and adjacent normal tissues (Figure 1b). KEGG pathway analysis revealed that IncRNA DLX6-AS1was involved in cell proliferation process through JAK/STAT signaling pathway (Figure 1c). The molecular mechanism will be clarified in our further study.

\section{Correlation between IncRNA DLX6-AS1 expression levels and clinical characteristics}

GO annotation and KEGG pathway analysis indicated that aberrantly expressed of lncRNA DLX6-AS1 affected biological processes of lung adenocarcinoma. To validate the microarray data, we analyzed DLX6-AS1 expression in 72 paired LAC and adjacent normal lung tissues using qRT-PCR. We calculated the relative expression of lncRNA with the comparative cycle threshold $(\mathrm{Ct})\left(2^{-\Delta \mathrm{Ct}}\right)$ method, and fold changes of $\geq 2$ were designated as up-regulated. Up-regulation of DLX6-AS1 was detected in $83.33 \%$ $(60 / 72)$ of LAC tissues compared with adjacent normal tissues, while $16.67 \%$ (12/72) displayed either downregulation or unobvious alteration. DLX6-AS1 expression in LAC tissues was conclusively proved a higher level than that in paired adjacent normal lung tissues $(\mathrm{Z}=-7.273, P=0.000$, Figure 2a), while DLX6 mRNA showed a similar trend $(Z=-7.374, P=0.000$, Figure $2 d)$. Statistical analysis revealed that DLX6-AS1 and DLX6 mRNA expression levels were significantly associated with both histological differentiation $(P=0.004$, Figure $2 \mathrm{~b}$; $P=0.000$, Figure $2 \mathrm{e})$ and TNM stage $(P=0.033$, Figure 2 c;

Table 1 Part of IncRNAs detected using microarray in three LAC patients

\begin{tabular}{|c|c|c|c|}
\hline \multicolumn{2}{|c|}{ Upregulated in cancer } & \multicolumn{2}{|c|}{ Downregulated in cancer } \\
\hline IncRNAs & $\log _{2}$ fold change $(T / N)$ & IncRNAs & $\log _{2}$ fold change (T/N) \\
\hline LOC 145757 & 4.1850148 & ANKRD20A5P & -2.416844 \\
\hline DLX6-AS1 & 3.893559 & C22orf34 & -2.4658422 \\
\hline LOC284801 & 3.6185247 & MAGI2-AS3 & -2.565988 \\
\hline KIAA1908 & 3.4127824 & LOC100505495 & -3.384433 \\
\hline XLOC_008466 & 3.2270826 & MGC27382 & -4.104419 \\
\hline PRSS30P & 3.149014 & LOC400550 & -4.5237017 \\
\hline LINC00665 & 2.945509 & XLOC_001412 & -4.6995843 \\
\hline RGMB-AS1 & 2.6495147 & XLOC_I2_006399 & -4.907096 \\
\hline HOTAIR & 2.581743 & RP11-165H20.1 & -5.3639335 \\
\hline
\end{tabular}



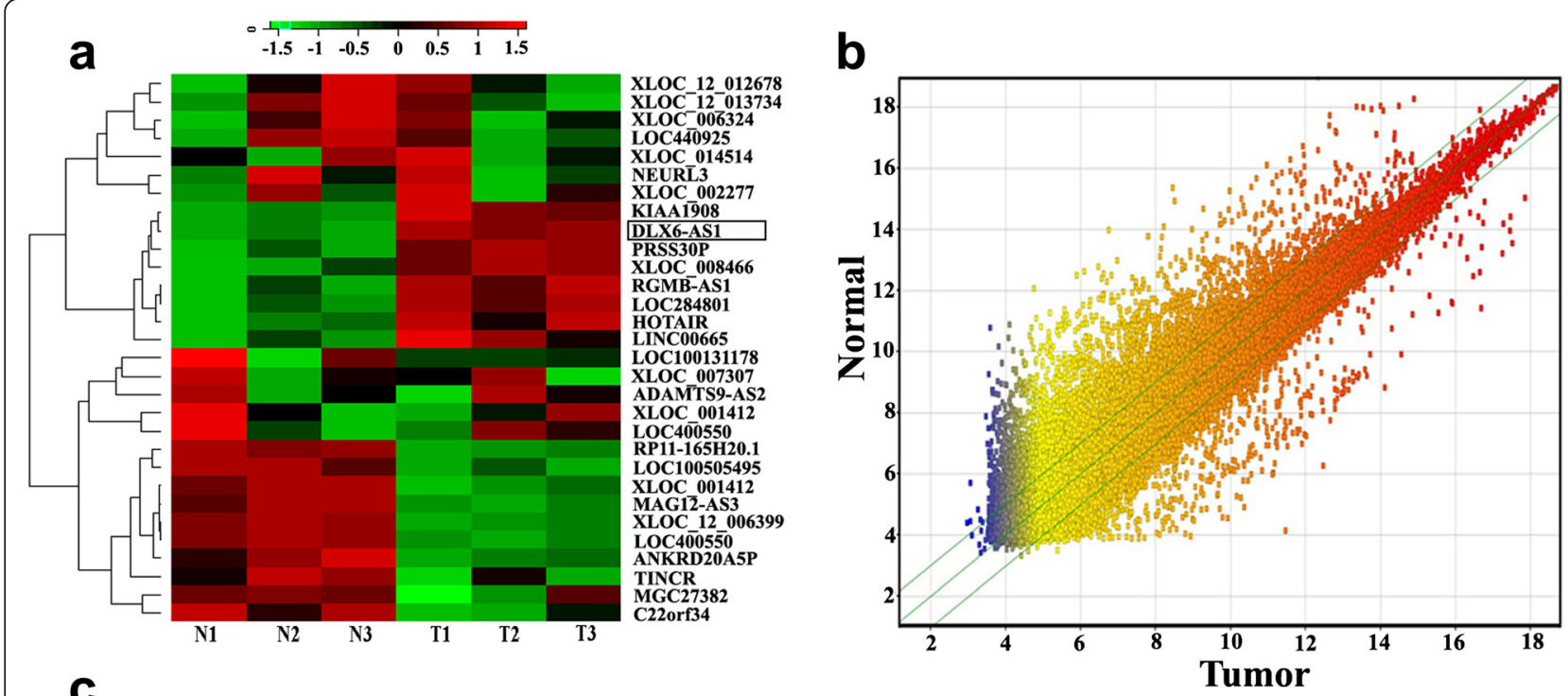

C

JAK-STAT SIGNALING PATHWAY

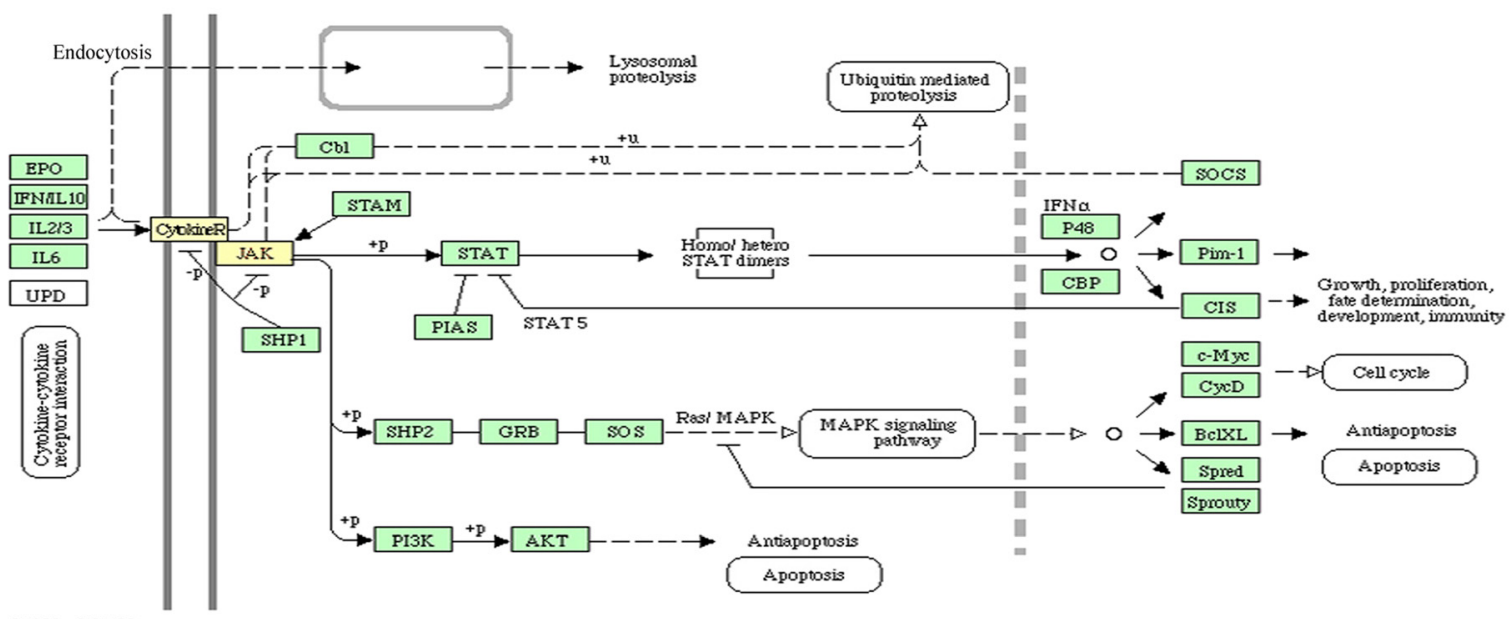

04630313109
(c) Kanehisa Laboratonies

Figure 1 Microarray data analysis. a The result from Hierarchical Clustering showed part of the distinguishable IncRNA expression profiles among 3 paired LAC and adjacent normal tissues. "Red" indicates high relative expression; and "green" indicates low relative expression. b The scatter-plot was used for assessing the IncRNA expression variation among 3 paired LAC and adjacent normal tissues. The values of $x$-axis and $y$-axis in the scatter-plot were the normalized signal values of each sample (log 2 scaled). The green lines are fold change lines (the default fold change value given is 2.0). The IncRNAs above the top green line and below the bottom green line indicated > 2.0-fold change in expression of IncRNAs among the 3 compared samples. "Red" denotes high relative expression levels, and "blue" denotes low relative expression levels. c KEGG pathway analysis revealed that IncRNA DLX6-AS1 was involved in cell proliferation process with JAK/STAT signaling pathway. The yellow squares represent key elements in cell proliferation progression.

$P=0.001$, Figure $2 \mathrm{f})$. No correlation was found with other clinicopathological features including age, gender, and lymph node metastasis (Table 2).

\section{Down-regulation the expression of IncRNA DLX6-AS1 decreased DLX6 mRNA and protein levels}

In most samples, the expression levels of lncRNA DLX6-AS1 were higher in tumor tissues than adjacent normal tissues. Thus, we speculated that DLX6-AS1 was an oncogene and knockdown of DLX6-AS1 decreased
DLX6 expression. To test it, we investigated the changes of DLX6 mRNA and protein levels after A549 and H1650 cells were transfected with siRNA targeting lncRNA DLX6-AS1 (si-LncRNA groups), negative control (NC groups) blank. Blank group were set as well. qRT-PCR analysis revealed that lncRNA DLX6-AS1 expression levels in si-LncRNA groups were significantly lower, compared to $\mathrm{NC}$ and Blank groups (Figure 3a: A549, $\chi^{2}=19.481, P=0.000$; Figure 3d: H1650, $\chi^{2}=19.564$, $P=0.001)$. qRT-PCR and Western blotting analysis showed 

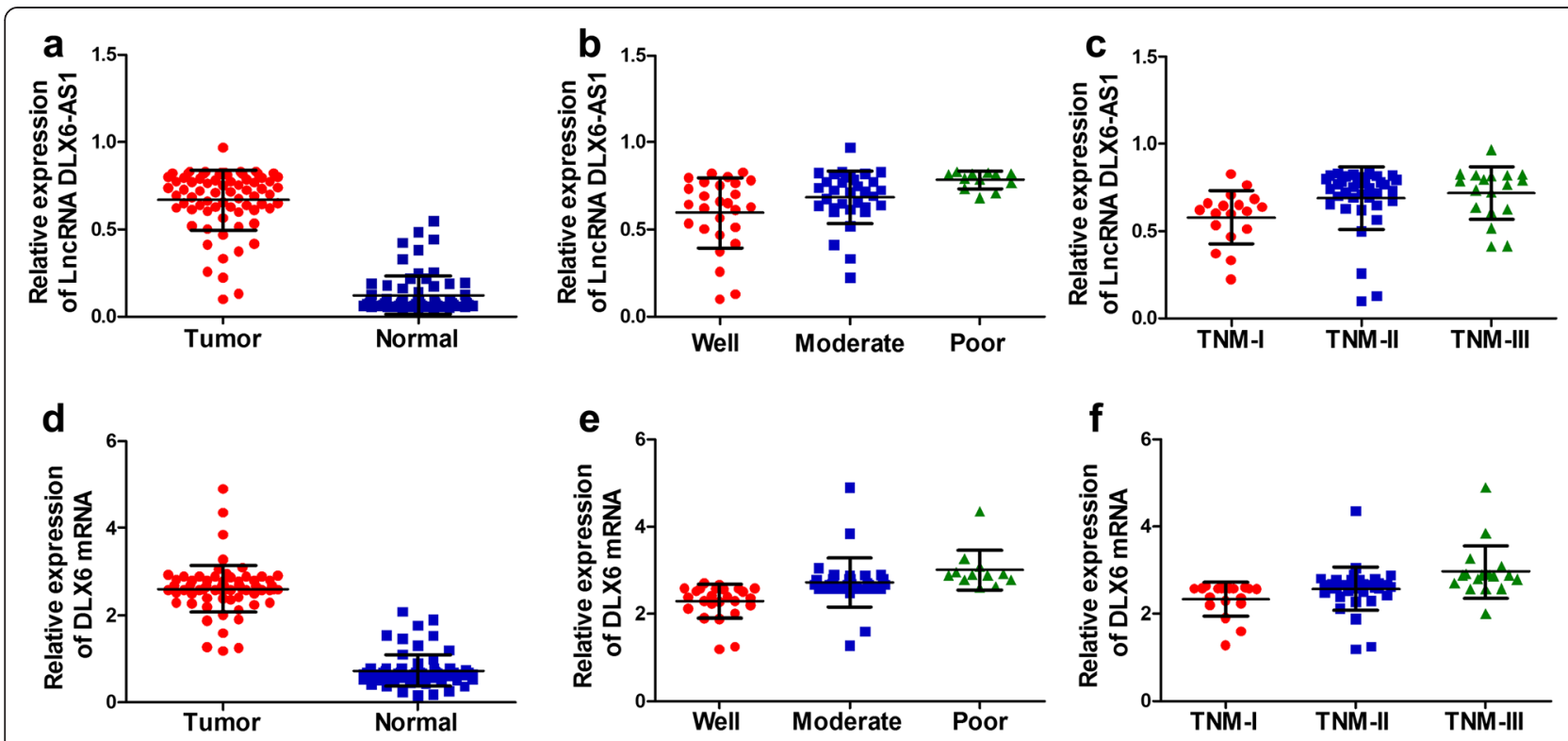

Figure 2 The expression levels of IncRNA DLX6-AS1 in lung adenocarcinoma tissues and adjacent normal lung tissues. a The expression levels of InCRNA DLX6-AS1 in paired LAC tissues and adjacent normal lung tissues were determined by qRT-PCR $\left(2^{-\Delta C t}\right)$. Statistically significant differences were observed $\left({ }^{*} P<0.05\right)$. b LnCRNA DLX6-AS1 expression levels were significantly associated with histological differentiation $\left({ }^{*} P<0.05\right)$. c The expression levels of IncRNA DLX6-AS1 were associated with TNM stage $\left.{ }^{*} P<0.05\right)$. $\mathbf{d}$ DLX6 mRNA levels in paired LAC tissues and adjacent normal lung tissues were determined by qRT-PCR $\left({ }^{*} P<0.05\right)$. e DLX6 mRNA levels were significantly associated with histological differentiation $\left({ }^{*} P<0.05\right)$. f DLX6 mRNA levels were associated with TNM stage $\left({ }^{*} P<0.05\right)$. Tumor: tumor tissue; Normal: adjacent normal lung tissue.

Table 2 LncRNA DLX6-AS1 and DLX6 mRNA expression levels were associated with clinicopathological features of LAC Patients

\begin{tabular}{|c|c|c|c|c|c|}
\hline \multirow[t]{2}{*}{$\begin{array}{l}\text { Clinicopathological } \\
\text { factor }\end{array}$} & \multirow[t]{2}{*}{$\mathbf{n}$} & \multicolumn{2}{|c|}{$\begin{array}{l}\text { LncRNA DLX6-AS1 } \\
\text { expression }\left(2^{-\Delta C t}\right)\end{array}$} & \multicolumn{2}{|c|}{$\begin{array}{c}\text { DLX6 mRNA } \\
\text { expression }\left(2^{-\Delta C t}\right)\end{array}$} \\
\hline & & Median \pm SD & $P$-Vale & Media \pm SD & $P$-Value \\
\hline \multicolumn{6}{|l|}{ Gender } \\
\hline Male & 35 & $0.6452 \pm 0.1905$ & 0.249 & $2.5103 \pm 0.4123$ & 0.149 \\
\hline Female & 37 & $0.6926 \pm 0.1541$ & & $2.6941 \pm 0.6363$ & \\
\hline \multicolumn{6}{|l|}{ Age (years) } \\
\hline$\geq 60$ & 34 & $0.6762 \pm 0.1837$ & 0.762 & $2.6426 \pm 0.6820$ & 0.591 \\
\hline$<60$ & 38 & $0.6637 \pm 0.1655$ & & $2.5709 \pm 0.3863$ & \\
\hline \multicolumn{6}{|l|}{ Differentiation } \\
\hline Well & 27 & $0.5965 \pm 0.2017$ & $0.004^{*}$ & $2.2947 \pm 0.3855$ & $0.000^{*}$ \\
\hline Moderate & 33 & $0.6873 \pm 0.1510$ & & $2.7153 \pm 0.5559$ & \\
\hline Poor & 12 & $0.7852 \pm 0.4988$ & & $2.9984 \pm 0.4624$ & \\
\hline \multicolumn{6}{|l|}{ Lymph node metastasis } \\
\hline Positive & 33 & $0.7078 \pm 0.1259$ & 0.075 & $2.7230 \pm 0.5027$ & 0.087 \\
\hline Negative & 39 & $0.6373 \pm 0.2009$ & & $2.5047 \pm 0.5625$ & \\
\hline \multicolumn{6}{|l|}{ TNM stage } \\
\hline I & 18 & $0.5806 \pm 0.1533$ & $0.033^{*}$ & $2.3290 \pm 0.3853$ & $0.001^{*}$ \\
\hline$\|$ & 36 & $0.6897 \pm 0.1806$ & & $2.5641 \pm 0.4939$ & \\
\hline III & 18 & $0.7184 \pm 0.1512$ & & $2.9618 \pm 0.6028$ & \\
\hline
\end{tabular}



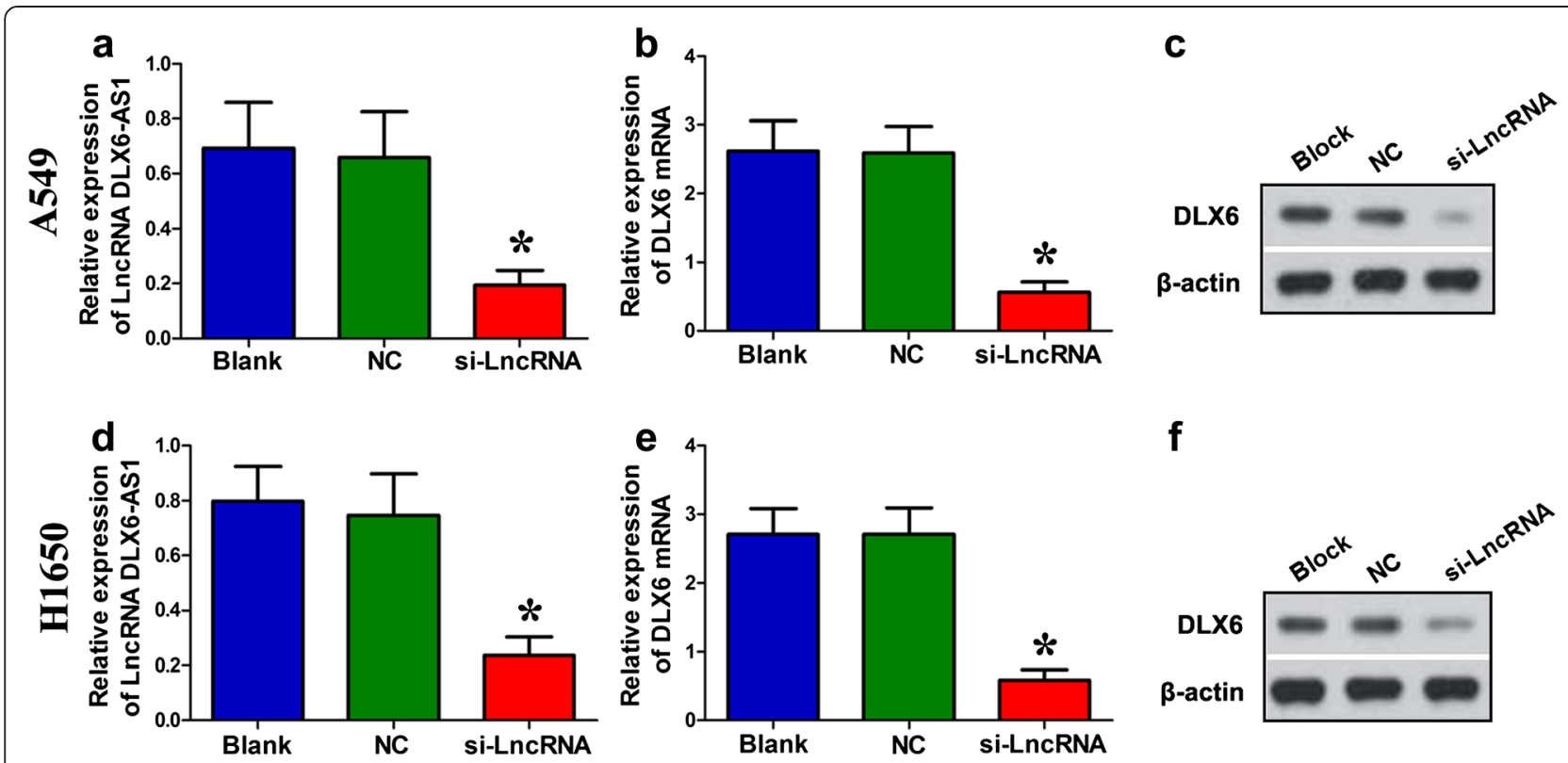

f

Figure 3 Down-regulation the expression of IncRNA DLX6-AS1 decreased the DLX6 protein levels. a Using qRT-PCR analysis in A549 cells, the expression levels of IncRNA DLX6-AS1 in si-LncRNA group were significantly lower, compared to NC and Blank groups ( $\left.{ }^{*} P<0.05\right)$. $\mathbf{b}$ DLX6 mRNA expression in si-LncRNA group was also lower than in the NC and Blank groups in A549 cells by qRT-PCR $(* P<0.05)$. $\mathbf{c}$ Western blotting analysis showed that DLX6 protein levels in si-LncRNA group were also lower than NC and Blank groups in A549 cells ( $\left.{ }^{*} P<0.05\right)$. $\beta$-actin was used as an endogenous reference. $\mathbf{d}$ qRT-PCR analysis verified that the expression level of IncRNA DLX6-AS1 in si-LncRNA group was significantly lower, compared to NC and Blank groups in H1650 cells ( $\left.{ }^{*} P<0.05\right)$. e DLX6 mRNA expression in si-LncRNA group was also lower than in NC and Blank groups in H1650 cells by qRT-PCR $\left({ }^{*} P<0.05\right)$. f Western blotting analysis showed that DLX6 protein levels in si-LncRNA group were also lower than in the NC and Blank groups in H1650 cells $\left({ }^{*} P<0.05\right)$. si-LncRNA group: cells transfected with siRNA targeting IncRNA DLX6-AS1; NC group: cells transfected with negative control siRNA; Blank group: non-transfected cells.

that DLX6 mRNA and protein levels were significantly lower in si-lncRNA groups than in NC and Blank groups (Figure 3b, c, e, and f).

\section{Discussion}

In recent years, genome-wide surveys have revealed that there are over 3000 human lncRNAs longer than $200 \mathrm{nt}$, but less than $1 \%$ have been characterized [33,34]. Although only a minority have been characterized in details, recent studies have indicated that lncRNAs were key players in gene regulatory processes and could influence both normal and transformed cellular function [35,36]. Several studies have further demonstrated that lncRNAs were efficiently regulated during cellular development in response to diverse signalings, and dysregulation of lncRNAs might also affect epigenetic information and provide advantages for cellular growth, resulting in progressive and uncontrolled tumor growth [17,29,36,37]. Thus, identification of tumor associated lncRNAs, which might be novel therapeutic targets, is critical for recognizing the roles of lncRNAs in tumorigenesis [38]. Based on microarray data analysis, our attention was focused on the lncRNA DLX6-AS1.

DLX gene family contains a homeobox related to Drosophila distal-less (Dll), a gene expressed in the head and limbs of developmental fruit fly. DLX genes, the vertebrate homologues of Dll, comprise a family of homeobox transcription factors involved in cell differentiation and morphogenesis. In humans, six distal-less homeobox (DLX) genes exist, represented by three bi-gene clusters, DLX1/DLX2, DLX5/DLX6, and DLX3/DLX4. Deregulation of DLX genes, including DLX4 and DLX5, was found in human solid tumors and hematologic malignancies, which indicated that DLX played an important role in tumor growth and progression [39-44]. So far, the functions of DLX6 haven't been reported in related researches, not to mention its expression level and working mechanisms in lung cancer.

In this study, microarray analysis suggested that the expression level of lncRNA DLX6-AS1 was higher in three LAC tissues than that in the paired adjacent normal lung tissues. qRT-PCR was performed to investigate lncRNA DLX6-AS1 expression levels in 72 LAC patients who hadn't received radiotherapy or chenmotherapy before. Correlation of lncRNA DLX6-AS1 expression levels and clinicopathological characteristics was then analyzed. Results showed that DLX6-AS1 expression was increased in LAC tissues compared with adjacent nontumor tissues, which indicated its possible participation in carcinogenesis. Besides, DLX6-AS1 expression levels 
showed close correlation with LAC histological grade and TNM stage. High DLX6-AS1 expression levels were more likely to be detected in tumors with advanced histological grade, and TNM III, suggesting that DLX6AS1 might participate in LAC invasion and metastasis. Taken together all the evidences, DLX6-AS1 was proposed to play a vital role in LAC carcinogenesis and progression. After transfection with siRNA of lncRNA DLX6-AS1, qRT-PCR and Western blotting analysis discovered that DLX6 mRNA and protein expression were decreased in A549 and H1650 cells compared to the NC and Blank groups. Based on our research data, lncRNA DLX6-AS1 was probably a novel therapeutic target for LAC patients. But the detailed molecular mechanism remains unclear. Our further studies will put more efforts on exploring the potential roles of lncRNA DLX6-AS1 in LAC development.

\section{Conclusions}

Microarray analysis identified that lncRNA DLX6-AS1 was up-regulated in LAC tissues. High DLX6-AS1 expression levels were significantly associated with both histological differentiation and TNM stage. Down-regulation of IncRNA DLX6-AS1 expression decreased the DLX6 mRNA and protein levels.

\section{Materials and methods}

\section{Patient samples collection}

72 paired LAC tissues and adjacent normal lung tissues (located more than $5 \mathrm{~cm}$ away from the tumors) were obtained from patients who underwent primary surgical resections between March 2012 and January 2014 at the First Affiliated Hospital of Zhengzhou University. None of the patients had received preoperative adjuvant therapy. Resected tissue samples were immediately frozen in liquid nitrogen and stored at $-80^{\circ} \mathrm{C}$ before RNA extraction. All the diagnoses of LAC and adjacent normal lung tissues were histopathologically confirmed. Prior informed consents and approval from the ethics committee of Zhengzhou University were obtained for the use of clinical samples for research purposes.

\section{Microarray assay}

Paired cancer tissues and adjacent normal tissues from three patients were randomly pooled and hybridized to chips. LncRNA microarray assays were performed by Biotechnology Corporation (Shanghai, China).Total RNA was amplified and labeled by Low Input Quick Amp Labeling Kit, One-Color (Agilent technologies), following the manufacturer's instructions. Labeled cDNA were purified by RNeasy mini kit (QIAGEN, Germany). After 17 hours' hybridization, slides were washed with Gene Expression Wash Buffer Kit (Agilent technologies), following the manufacturer's instructions. Slides were scanned by Agilent Microarray Scanner (Agilent technologies) with default settings. Data were extracted with Feature Extraction software 10.7 (Agilent technologies).

\section{RNA extraction and quantitative real-time fluorescent}

To further certify the generality of lncRNAs expression pattern, specimens from 72 patients were used to perform qRT-PCR assay. Total RNA was extracted from frozen specimens using TRIzol reagent (Invitrogen, USA) according to the manufacturer's protocol. qRT-PCR was performed using an ABI 7500 thermal cycler, according to the manufacturer's recommendations. Each qRT-PCR experiment was repeated three times. The primers selected as the followings: IncRNA DLX6-AS1, forward, 5'-AGTTTCTCTCTAGATTGCCTT-3'; reverse, 5'-ATT GACATGTTAGTGCCCTT -3'. DLX6, forward, 5'-TC CACACCAGGACACGATGC-3', reverse, 5'-CTTGCC ACACTTATGAGCTCT-3'. GAPDH, forward, 5'-AGA GGCAGGGATGATGTTCTG -3', reverse, 5'-GACTC ATGACCACAGTCCATGC-3'. Relative expression of genes was calculated using the comparative cycle threshold (Ct) $\left(2^{-\Delta \mathrm{Ct}}, \Delta \mathrm{Ct}=\mathrm{Ct}\right.$ median IncRNA or mRNA-Ct median GAPDH) method with glyceraldehyde-3-phosphate dehydrogenase (GAPDH), as the endogenous control [45].

\section{Cell culture}

Human lung adenocarcinoma cell lines A549 and H1650 were purchased from the Type Culture Collection of the Chinese Academy of Sciences (Shanghai, China). Cells were cultured in RPMI1640 (Gibco, USA) medium supplemented with $10 \%$ fetal bovine serum (FBS), $100 \mathrm{U} / \mathrm{ml}$ penicillin and $100 \mu \mathrm{g} / \mathrm{ml}$ streptomycin (Enpromise, China) in humidified air with $5 \% \mathrm{CO}_{2}$ at $37^{\circ} \mathrm{C}$.

\section{SiRNA transfection}

Specific siRNAs targeting lncRNA DLX6-AS1 and the negative control siRNAs were designed and synthesized by GenePharma (Shanghai, China). Cells were plated in 6-well plates in antibiotic-free growth medium supplemented with 10\% FBS and cultured until 50-70\% confluent overnight. The siRNAs were transfected into cultured cells using Lipofectamine 2000 (Invitrogen, USA) according to the manufacturer's instructions. Forty-eight hours after transfection, cells were harvested for qRT-PCR or Western blotting analysis.

\section{Western blotting}

Cells were washed twice with PBS solution, and then were lysed with RIPA Lysis Buffer (Beyotime, China) containing phenylmethanesulfonylfluoride (PMSF). Protein concentrations were determined with Pierce BCA Protein Assay Kit (Beyotime, Haimen, China). Proteins were subjected to $12 \%$ sodium dodecyl sulfate polyacrylamide gel electrophoresis (SDS-PAGE) and transferred 
onto PVDF membranes. Membranes were blocked for $1 \mathrm{~h}$ in phosphate-buffered saline/Tween-20 containing $5 \%$ non-fat milk. The membranes were incubated overnight at $4^{\circ} \mathrm{C}$ with 1:500 dilutions of the primary antibodies (rabbit anti-human DLX6 antibody, 1:500, Santa Cruz Biotechnology). Following extensive washing with TBST, secondary antibodies were incubated at room temperature for $1 \mathrm{~h}$ (HRP labeled goat anti-rabbit IgG, 1:1000, Santa Cruz Biotechnology). Membranes were washed with Tween 20-PBS four times (15 min each) at room temperature. Signals were determined using a chemiluminescence detection kit (Amersham Pharmacia Biotech, Piscataway, NJ). Protein levels were normalized to $\beta$-actin.

\section{Statistical analysis}

Statistical analysis was conducted with the assistance of SPSS 17.0 software. All data were expressed as means \pm standard deviation (SD). The differences between paired samples were analyzed using Wilcoxon signed-rank test. The differences between diverse independent groups were analyzed using Kruskal-Wallis test. For multiple comparisons, Tamhane'T2 (M) was used in the comparison of the parental and control vector groups. $P<0.05$ was considered to be statistically significant.

\section{Competing interests}

The authors declare that they have no competing interests.

\section{Authors' contributions}

GJZ and GQZ, and JL: conceived of the study, and participated in its design and coordination and helped to draft the manuscript. JL, PL, WZ, RY, SSC, YB and SZD: collected the samples. JL, PL, XNC, YWD, YYW and WQZ: carried out part of experiments and wrote the manuscript. YYW, GJZ and GQZ performed the statistical analysis. All authors read and approved the final manuscript.

\section{Acknowledgements}

The authors are grateful to all staff at the study center who contributed to this study. This study was supported by Ministry of Major Science \& Technology of Henan (201401005).

\section{Author details}

${ }^{1}$ Department of Respiratory Medicine, The First Affiliated Hospital of Zhengzhou University, Zhengzhou, Henan, China. 'Department of Pediatric Surgery, The First Affiliated Hospital of Zhengzhou University, Zhengzhou, Henan, China. ${ }^{3}$ College of Basic Medical Sciences, Zhengzhou University, Zhengzhou, Henan, China.

Received: 15 December 2014 Accepted: 22 April 2015

Published online: 02 May 2015

\section{References}

1. Chen WQ, Zheng RS, Zhang SW, Zou XN, Zhao P, He J. Lung cancer incidence and mortality in China. Thorac Cancer. 2013:4:102-8.

2. Jemal A, Siegel R, Xu J, Ward E. Cancer statistic. CA Cancer J Clin. 2010;60:277-300.

3. Siegel R, Ma J, Zou Z, Jemal A. Cancer statistics 2014. CA Cancer J Clin. 2014;64:9-29.

4. DeSantis CE, Lin CC, Mariotto AB, Siegel RL, Stein KD, Kramer JL, et al. Cancer treatment and survivorship statistics. CA Cancer J Clin. 2014;64(4):252-71.

5. Pastorino U. Lung cancer screening. Br J Cancer. 2010;102:1681-6.
6. Travis WD. Pathology of lung cancer. Clin Chest Med. 2011;32:669-92.

7. Liu XH, Lu KH, Wang KM, Sun M, Zhang EB, Yang JS, et al. MicroRNA-196a promotes non-small cell lung cancer cell proliferation and invasion through targeting HOXA5. BMC Cancer. 2012;12:348.

8. Gutschner T, Hammerle M, Eissmann M, Hsu J, Kim Y, Hung G, et al. The non-coding RNA MALAT1 is a critical regulator of the metastasis phenotype of lung cancer cells. Cancer Res. 2013;73(3):1180-9.

9. Van Roosbroeck K, Pollet J, Calin GA. MiRNAs and long noncoding RNAs as biomarkers in human diseases. Expert Rev Mol Diagn. 2013;13:183-204.

10. International Human Genome Sequencing C. Finishing the euchromatic sequence of the human genome. Nature. 2004;431:931-45.

11. Mattick JS, Makunin IV. Non-coding RNA. Hum Mol Genet. 2006;15(Spec No 1):R17-29.

12. Eddy SR. Non-coding RNA genes and the modern RNA world. Nat Rev Genet. 2001;2:919-29.

13. Gupta RA, Shah N, Wang KC, Kim J, Horlings HM, Wong DJ, et al. Long non-coding RNA HOTAIR reprogramschromatin state to promote cancer metastasis. Nature. 2010;464(7291):1071-6.

14. Loewer S, Cabili MN, Guttman M, Loh YH, Thomas K, Park IH, et al. Large intergenic non-coding RNA-RoR modulates reprogramming of human induced pluripotent stem cells. Nat Genet. 2010;42(12):1113-7.

15. Wang J, Liu X, Wu H, Ni P, Gu Z, Qiao Y, et al. CREB upregulates long non-coding RNA, HULC expression through interaction withmicroRNA-372 in liver cancer. Nucleic Acids Res. 2010;38(16):5366-83.

16. Khaitan D, Dinger ME, Mazar J, Crawford J, Smith MA, Mattick JS, et al. The melanoma-upregulated long noncoding RNA SPRY4-IT1 modulates apoptosis and invasion. Cancer Res. 2011;71(11):3852-62.

17. Yang F, Zhang L, Huo XS, Yuan JH, Xu D, Yuan SX, et al. Long noncoding RNA high expression in hepatocellular carcinoma facilitates tumor growth through enhancer of zeste homolog 2 in humans. Hepatology. 2011;54(5):1679-89.

18. Cui Z, Ren S, Lu J, Wang F, Xu W, Sun Y, et al. The prostate cancer-up-regulated long noncoding RNA PIncRNA-1 modulates apoptosis and proliferation through reciprocal regulation of androgen receptor. Urol Oncol. 2013;31(7):1117-23.

19. Wang Y, Chen W, Yang C, Wu W, Wu S, Qin X, et al. Long non-coding RNA UCA1a (CUDR) promotes proliferation and tumorigenesis of bladder cancer. Int J Oncol. 2012;41(1):276-84.

20. Jin G, Sun J, Isaacs SD, Wiley KE, Kim ST, Chu LW, et al. Human polymorphisms at long non-coding RNAs (IncRNAs) and association with prostate cancer risk. Carcinogenesis. 2011;32(11):1655-9.

21. Geng YJ, Xie SL, Li Q, Ma J, Wang GY. Large intervening non-coding RNA HOTAIR is associated with hepatocellular carcinoma progression. J IntMed Res. 2011;39(6):2119-28.

22. Li $X$, Jiang XY, Ge J, Wang J, Chen GJ, Xu L, et al. Aberrantly expressed IncRNAs in primary varicose great saphenous veins. PLOS ONE. 2014;9:e86156.

23. Dong R, Jia D, Xue P, Cui X, Li K, Zheng S, et al. Genome-wide analysis of long noncoding RNA (IncRNA) expression in hepatoblastoma tissues. PLOS ONE. 2014;9:e85599.

24. Crea F, Watahiki A, Quagliata L, Xue H, Pikor L, Parolia A, et al. Identification of a long non-coding RNA as a novel biomarker and potential therapeutic target for metastatic prostate cancer. Oncotarget. 2014;5:764-74.

25. Ren S, Wang F, Shen J, Sun Y, Xu W, Lu J, et al. Long non-coding RNA metastasis associated in lung adenocarcinoma transcript 1 derived miniRNA as a novel plasma-based biomarker for diagnosing prostate cancer. Eur J Cancer. 2013;49:2949-59.

26. Cao WJ, Wu HL, He BS, Zhang YS, Zhang ZY. Analysis of long non-coding RNA expression profiles in gastric cancer. World J Gastroenterol. 2013;19:3658-64.

27. Jiang YJ, Bikle DD. LncRNA: a new player in 1a, $25(\mathrm{OH}) 2$ vitamin D3/NDR protection against skin cancer formation. Exp Dermatol. 2014;23:147-50.

28. Kim K, Jutooru I, Chadalapaka G, Johnson G, Frank J, Burghardt R, et al. HOTAIR is a negative prognostic factor and exhibits prooncogenic activity in pancreatic cancer. Oncogene. 2013;32(13):1616-25.

29. Ji P, Diederichs S, Wang W, Boing S, Metzger R, Schneider PM, et al. MALAT-1, a novel noncoding RNA, and thymosin beta 4 predict metastasis and survival in early-stage non-small cell lung cancer. Oncogene. 2003;22(39):8031-41.

30. Takahashi Y, Sawada G, Kurashige J, Uchi R, Matsumura T, Ueo H, et al. Amplification of PVT-1 is involved in poor prognosis via apoptosis inhibition in colorectal cancers. Br J Cancer. 2014;110:164-71.

31. Lin R, Maeda S, Liu C, Karin M, Edgington TS. A large noncoding RNA is a marker for murine hepatocellular carcinomas and a spectrum of human carcinomas. Oncogene. 2007;26(6):851-8. 
32. Ponting CP, Oliver PL, Reik W. Evolution and functions of long noncoding RNAs. Cell. 2009;136(4):629-41.

33. Khalil AM, Guttman M, Huarte M, Garber M, Raj A, Rivea Morales D, et al. Many human large intergenic noncoding RNAs associate with chromatin-modifying complexes and affect gene expression. Proc Natl Acad Sci U S A. 2009;106(28):11667-72.

34. Perez DS, Hoage TR, Pritchett JR, Ducharme SAL, Halling ML, Ganapathiraju SC, et al. Abundantly expressed non-coding transcripts are altered in cancer. Hum Mol Genet. 2008;17:642-55.

35. Guttman M, Donaghey J, Carey BW, Garber M, Grenier JK, Munson G, et al. IncRNAs act in the circuitry controlling pluripotency and differentiation. Nature. 2011;477:295-300.

36. Yuan SX, Yang F, Yang Y, Tao QF, Zhang J, Huang G, et al. Long non-coding RNA-MVIH promotes angiogenesis and serves as a predictor for HCC patients' poor recurrence-free survival after hepatectomy. Hepatology. 2012;56(6):2231-41.

37. Spizzo R, Almeida MI, Colombatti A, Calin GA. Long non-coding RNAs and cancer: a new frontier of translational research? Oncogene. 2012;31:4577-87.

38. Hara F, Samuel S, Liu J, Rosen D, Langley RR, Naora H. A homeobox gene related to Drosophila distal-less promotes ovarian tumorigenicity by inducing expression of vascular endothelial growth factor and fibroblast growth factor-2. Am J Pathol. 2007;170:1594-606.

39. Man YG, Fu SW, Schwartz A, Pinzone JJ, Simmens SJ, Berg PE. Expression of BP1, a novel homeobox gene, correlates with breast cancer progression and invasion. Breast Cancer Res Treat. 2005;90:241-7.

40. Tan Y, Timakhov RA, Rao M, Altomare DA, Xu J, Liu Z, et al. A novel recurrent chromosomal inversion implicates the homeobox gene Dlx5 in T-cell lymphomas from Lck-Akt2 transgenic mice. Cancer Res. 2008;68:1296-302.

41. Tan Y, Cheung M, Pei J, Menges CW, Godwin AK, Testa JR. Upregulation of DLX5 promotes ovarian cancer cell proliferation by enhancing IRS-2-AKT signaling. Cancer Res. 2010;70:9197-206.

42. Kato T, Sato N, Takano A, Miyamoto M, Nishimura H, Tsuchiya E, et al. Activation of placenta-specific transcription factor distal-less homeobox 5 predicts clinical outcome in primary lung cancer patients. Clin Cancer Res. 2008;14:2363-70.

43. Morini M, Astigiano S, Gitton Y, Emionite L, Mirisola V, Levi G, et al. Mutually exclusive expression of DLX2 and DLX5/6 is associated with the metastatic potential of the human breast cancer cell line MDA-MB-231. BMC Cancer. 2010;10:649.

44. Xu J, Testa JR. DLX5 (distal-less homeobox 5) promotes tumor cell proliferation by transcriptionally regulating MYC. J Biol Chem. 2009:284:20593-601.

45. Schmittgen TD, Livak KJ. Analyzing real-time PCR data by the comparative C (T) method. Nat Protoc. 2008:3:1101-8

\section{Submit your next manuscript to BioMed Central and take full advantage of:}

- Convenient online submission

- Thorough peer review

- No space constraints or color figure charges

- Immediate publication on acceptance

- Inclusion in PubMed, CAS, Scopus and Google Scholar

- Research which is freely available for redistribution 